\title{
Reflections on Effective Teaching
}

\author{
Huaqiong $\mathrm{Xu}^{1}$, Zhongfeng $\mathrm{Hu}^{2}$ \\ ${ }^{1}$ Leisure Sports and Management Department, Guangzhou Institute of Physical Education, Guangzhou, China \\ ${ }^{2}$ School of Public Administration, South China Normal University, Guangzhou, China
}

Email address:

xhq020@163.com (Huaqiong Xu)

\section{To cite this article:}

Huaqiong Xu, Zhongfeng Hu. Reflections on Effective Teaching. Science Journal of Education. Vol. 3, No. 4, 2015, pp. 95-99. doi: $10.11648 /$ j.sjedu.20150304.15

\begin{abstract}
People focus on effective teaching in the new curriculum reform in China. The understanding of the implication of effective teaching is diverse, but we should make clear in some problems. The evaluation standards for effective teaching are keeping pace with the times according to the influencing factors which include students' learning, teachers' teaching, learning content and learning environment. The implementation of effective teaching should be on the basis of "three-dimensional object", promote effective interaction between teachers and students, focus on the selection and design of learning content, create effective learning environment for students and conduct integration of various research methods.
\end{abstract}

Keywords: Effective Teaching, Evaluation Standard, Implementation, Reflection

\section{What is Effective Teaching}

Through the systematic study of the effective teaching of the west, the scholars in our country found that the interpretation of effective teaching by the western scholars can be summarized as three basic orientations: target orientation, skill orientation and achievement orientation. But so far, effective teaching doesn't have an unified interpretation, it is difficult to find an optimal defining angle or framework.

Based on the different perspectives, domestic scholars define the effective teaching as following: (1) Define effective teaching from the relation between teaching input and teaching output. Such as Zhang, L. believes, effective teaching means that teachers follow the objective law of the teaching activity, achieve the teaching effect as much as possible through the time, energy and material input as little as possible, so as to achieve the specific teaching objectives and meet the needs of social and personal education value (Zhang, 2000). (2) Define effective teaching in the orientation of student development. Like Cui, Y. K. thinks, effective teaching means that students obtain the specific progress or development after teachers' teaching for a period of time, that is, whether students have progress or development is the only indicator of the effectiveness of teaching (Cui, 2001).Wu, Y. J. believes, effective teaching refers to the teaching that can promote students' development. From the nature of modern education, all teaching and learning must be based on students' development as a fundamental starting point and the ultimate destination, therefore, the ultimate judgment of valid and invalid is only students' development, rather than the time for completing the teaching task or something else ( $\mathrm{Wu}$, 2011). (3) Define effective teaching from the internal structure of effective teaching. Such as Long, B. X. and Chen, $X$. D. have analyzed effective teaching in three levels: the surface, middle and deep level. From the surface level, effective teaching is a kind of teaching form; from the middle level, effective teaching is a kind of teaching thinking; from the deep level, effective teaching is a kind of teaching ideal. The practice of effective teaching is to take effective "ideal" into effective "thinking", and then convert to an effective "state" (Long \& Chen, 2005). (4)Define effective teaching from the combining points of the effectiveness of teaching and learning. Such as Song, Q. Q. believes, effective teaching is the organized and implemented teaching activity that teachers and students comply with the objective law of teaching activity, promote students to get integrated, coordinated and sustainable progress and development in the "three-dimensional object" which includes knowledge and skills, process and methods, emotional attitude and values at the optimal speed, benefit and efficiency, so as to achieve the expected goal of teaching and meet the social and personal educational value needs(Song, 2007). Yang, Y. believes that it is more pertinent to define the effective teaching as the integration of the effectiveness of "teachers' teaching" and 
“students' learning (Yang, 2014).

In general, the understanding of the meaning of effective teaching by the current academia is not enough clear and comprehensive. With the implementation of the new curriculum reform, the understanding of the implication of effective teaching has not been fully adapted to the requirements of the times. In the new situation, the understanding of the implication of effective teaching must be clear in the following problems: Firstly, effective teaching should promote students to obtain comprehensive and coordinated development in the "three-dimensional object". "Three-dimensional object" is helpful to break the bondage of the teaching design of simple knowledge points, to enhance the subject teaching of primary and middle school from the level of "animal training" to the height of "human learning". And this is the original intention of promoting quality education. Secondly, "effective" in the effective teaching means efficiency, effectiveness and benefit. The efficiency, effectiveness and benefit are corresponding to the evaluation goal of different levels. The relation among them is progressive, which benefit is the highest or final goal, the common goal is "for students' development". Thirdly, form the effective teaching thinking that teaching and learning are equally important. The understanding of effective teaching for many scholars in the past was just a partial attention in "teaching" or "learning", which must make teaching from one extreme to the other, and was not conducive to the benign interaction between teaching and learning. The process of effective teaching is not only a process to teach students "learn to learn", but also a process to make teachers "learn to teach".

\section{How to Evaluate Effective Teaching}

\subsection{The Theoretical Basis for the Establishment of Evaluation Standards for Effective Teaching}

From a comprehensive overview of the current domestic and foreign research, the main theoretical basis of evaluation standards for effective teaching is the theory of constructivism. Constructivism is a modern theory based on cognitive psychology. Construction is more concerned about how the learners use the original experience, psychological structure and beliefs as base to construct their own unique spiritual world. It pays more attention to establish the situation that is helpful to initiatively explore the knowledge for the learners. According to the theory of constructivism, the evaluation standards for effective teaching pay attention not only to the achievement of the cognitive domain, but also to the function that the classroom teaching develop to form learners' emotion, attitude, value concept; pay attention not only to the evaluation of teaching results, but also to the evaluation of the process, the production and the diversity of the evaluation standards. Situational learning theory is also a constructivism theory that is close to the evaluation standards for effective teaching. It emphasizes that people have the ability to construct knowledge actively, study is two-way interactive process between people and environment, the construction of knowledge, skill and feeling develops in the interaction between the learner and the situation (Xiang, 2004).

\subsection{Analysis of Factors Influencing the Evaluation Standards for Effective Teaching}

The effectiveness of classroom teaching is mainly restricted by four kinds of factors, such as student, teacher, content and environment. And these factors are intertwined with each other(Sun, 2008).In the effective teaching process, these four kinds of factors should not only have their own role, but also interact with one another.

\subsubsection{Students'Learning}

The theory of constructivism has urged us to focus on the evaluation of effective teaching from the teachers' teaching to students' learning, because students' learning is the purpose of teaching. Effective teaching should give full play to the subject function of students, pay attention to students' emotional state, participating state, state of mind and state of learning reaching. Practice has proved that students with learning motivation and learning interest are more likely to succeed than students who are indifferent to learning (The Florida Center for Instructional Technology, 2013).Only students take part in the learning process as an equal participant, does real learning occur, can the students develop the positive emotional attitude, can the quality of autonomous learning be formed. The effectiveness of teaching must pay attention to whether students receive sustainable development and progress in the "three-dimensional object" which includes knowledge and skills, process and methods, emotional attitude and values.

\subsubsection{Teachers' Teaching}

Effective teaching is required to play a balance between teachers' leading role and students' main body playing. We advocate constructivism and taking the students as the center, and it in no way means that the teachers give up the responsibility of students' learning. Effective teaching should give full play to the leading role of the teachers. Teachers' teaching ideas, knowledge, teaching responsibility consciousness, teaching efficacy, teaching ability and teaching wit are important factors that affect effective teaching(Yao, 2004).Evaluating effective teaching from the perspective of teachers' teaching is helpful to improve teachers' teaching experience and teaching behavior, promote the teachers to establish development awareness, reflection consciousness, efficiency consciousness and characteristic consciousness, so as to make teachers' education ability to be able to improve continuously.

\subsubsection{Learning Content}

How to deal with learning content is one of the most important factors that lead to different learning achievement in many kinds of factors that affect classroom teaching. In the teaching process, the teachers in primary and middle school often think about the problem of "how to teach" in the heart. 
Teaching methods are important, however, efforts on teaching methods are finally in order to let the students learn some learning content. Evaluating the effectiveness of effective teaching from the perspective of learning content is helpful for the teachers to focus on "what to teach", and to achieve the most basic goal of classroom teaching, that is, "in every class, let the students learn the most, the most profound and the most valuable learning content" (Lu, 2012).

\subsubsection{Learning Environment}

Effective teaching requires us to create the learning environment that can lead students to initiatively participate in, to promote the interaction among teachers, students, content and environment. From the current practice in China, the importance of the environmental factor in the teaching is not fully recognized, and the indicator of the classroom environment is only a small proportion of the evaluation standards for effective teaching. In fact, the evaluation of the classroom environment can test the practical effect of classroom teaching. Whether do the teachers create the classroom environment which is beneficial to students' healthy development? Whether is the need for students' learning fully satisfied in the classroom? All of the above are required to make a scientific evaluation of the classroom environment.

\subsection{Reflections on the Evaluation Standards for Effective Teaching}

At present, there are some problems in the evaluation standards for effective teaching in China. Firstly, the theory and practice are out of line. Many theoretical researchers evaluate teachers' teaching behavior on the basis of the students and the learning. But in practice, the evaluation of effective teaching still focuses on teachers' various teaching behavior. Secondly, the evaluation standards ignore the emotional evaluation. The standards don't pay enough attention to whether the teachers take care of students' learning interest, whether the effective learning environment is created. Thirdly, the standards are lack of specific indicators, so they can not be a good guide for the teachers to improve practical teaching, can not promote teachers' professional development. Fourthly, the standards are lack of empirical research. The vast majority of our research is the theoretical thinking and design of the evaluation standards. The research of observation evaluation in the real classroom is very little. The evaluation standards and the indicators derived from theoretical deduction from top to bottom, not obtained the support of field observation data from bottom to top, so they were lack of reliability and validity ( $\mathrm{Xu} \& \mathrm{Hu}, 2010)$.

The evaluation standards for effective teaching are keeping pace with the times. The standards seem to depend on the tools and methods of the evaluation, but it is actually up to the evaluation view of the teaching subject and the effectiveness of the evaluation. "Effective" is a concept that is required to develop, to go beyond. There is no eternal "effective" teaching. With the development of the new curriculum reform in our country, the research on the evaluation standards for effective teaching must reflect the new teaching concept and evaluation view.

\section{How to Implement Effective Teaching}

The domestic and foreign academia has made extensive and profound research on the implementation strategies of effective teaching. American scholars Tiberius and Tipping proposed 12 principles on the basis of the past research(Tiberius \& Tipping,2010).In England, "the teaching research program center" has developed ten principles of implementation to guide the effective teaching(The Teaching and Learning Research Programme,2011). Effective teaching has become the focus in the new round of curriculum reform in the basic education in China. In the domestic research on effective teaching, the strategies of effective teaching mainly focus on the teaching process, multi-innovation, specific standards and specific subjects(Qiao, Tao, Zhang \& Shi,2008).But, in the implementation of effective teaching, a lot of strategies didn't achieve the desired results. Reflecting on the present situation of implementation of effective teaching in the primary and middle school, we think we should pay attention to the following points:

\subsection{Implement Effective Teaching on the Basis of the "Three-Dimensional Object"}

It has profound practical significance that we implore the implementation of effective teaching on the basis of the "three-dimensional object". It is helpful for us to really achieve the goals of alleviating the burden and increasing the effectiveness, to deepen the teaching reform. Teaching is the center of education, and learning knowledge is the basic goal of teaching. In order to achieve the "three-dimensional object", we should firstly achieve the goal of knowledge teaching, then achieve the development of ability, attitude and value, study process, learning method and other goals, achieve unity of the specific objectives, and finally achieve the comprehensive unity of the specific objectives of "three-dimensional object".(Hao,2009).

\subsection{Promote Effective Interaction Between Teachers and Students}

The quality and effect of the interaction between teachers and students directly affect success or failure of the whole classroom teaching. Effective teacher-student interaction can enhance students' learning effect, develop necessary social skills for students' future growth. In order to promote teacher-student interaction, teachers should change the traditional concept of "teachers' dignity", teachers and students treat each other in equal, respect each other's personality and freedom; teachers should communicate not only cognitive information, but also emotional information with students. The effective interaction between teachers and students require teachers to use a certain questioning skills: the question raised is instructive; ask all the students, including raising their hands and not raising their hands; set aside waiting time after asking question, especially for higher level question; apply inquiry method, encourage students to clarify their ideas and explain their reasoning...... 
(The Florida Center for Instructional Technology, 2013). In addition, teachers should provide students with descriptive, positive or specific feedback information.

\subsection{Focus on the Selection and Design of Learning Content}

Scholars in Hong Kong found that learning content was the internal factor that directly affects students' learning quality after they summed up hundreds of research on teaching reform(Yang,2006).The choice and design of the learning content directly affect students' learning effect. The learning content in the classroom teaching must be full of challenge and must be valuable, and it should greatly affect students' knowledge, ability or attitude. The theory of variation thinks that a person's understanding of one thing depends on the feature of the thing that he can focus on or identify with. Learning means to understand the learning content, that is, students must identify the specific "key feature" of the things (Li \& Gao, 2007).The reason hindering students from learning may be that students can not identify the key features of what they learn, or they are lack of experience that can help them to identify, or their original experience becomes the obstacles for their reidentification. Because people usually pay attention to the things that change, we can use different variation patterns (that is, what change, what don't change) to generate the functions of comparison, generalization, separation, and integration. And students more clearly identified the key features of the learning content, then enhance the learning effectiveness.

\subsection{Create Effective Learning Environment for Students}

A large number of domestic and foreign research results show that the classroom environment has direct and profound impact on students' development in cognitive, emotional, moral, social and creative aspects, and even exceeds the effect of students' background. In the current practice of our country, teachers are not fully aware of the importance of environmental factors in teaching. Effective classroom environment should reflect the features of equity, interaction and security. Equity means to take students as the main body, treat every student equally, not to give students the label of "a good student" or "a bad student", fully embody the concept of education equality. Interaction mainly embodies in the full interaction between students and teachers, students and students, students and learning content, students and environment. Security means to create a relaxed, friendly learning environment for students, let students speak their own mind freely, allow students to take risks and make mistakes, encourage innovative ideas, let every student experience success.

\subsection{Conduct Integration of Various Research Methods}

The research on the strategies of effective teaching should be more based on the empirical research method, or combination of speculative and empirical research method. Only general education researchers go deeply into the practice of classroom teaching, comprehensively use the speculative and empirical research method, obtain the feasible research results, and provide operational recommendations, can we better promote the implementation of effective teaching.

\section{References}

[1] Zhang, L. (2000). On the standards of effective teaching. Theory and Practice of Education, 11, 37.

[2] Cui, Y. K. (2001).Effective teaching: ideas and strategies(up).People's Education, 6, 46.

[3] Wu, Y. J. (2011). About the re-cognition of effective teaching. Curriculum, Teaching Material and Method, 7, 11.

[4] Long, B. X., \& Chen, X. D. (2005). Conceptual reconstruction and theoretical thinking of effective teaching. Journal of Educational Science of Hunan Normal University, 4, 39-42.

[5] Song, Q. Q. (2007). The implication and features of effective teaching. Exploring Education Development, 1A, 40.

[6] Yang, Y. (2014). Strategies and methods of effective teaching and effective learning. Curriculum, Teaching Material and Method, 3, 20.

[7] Xiang, G. F. (2004). Situated learning theory and modern teaching. Journal of Inner Mongolia Normal University(Education Science Edition), 6, 20.

[8] Sun, Y. L. (2008). Study on the effectiveness standards of classroom teaching. Beijing: Education Science Press.

[9] The Florida Center for Instructional Technology(FCIT).(2013).Attitude surveys. http://fcit.usf.edu/assessment/attitude/survey.html

[10] Yao, L. M. (2004). Teacher factor analysis of effective teaching. Journal of Higher Education Research, 1, 4.

[11] Lu, M. L. (2012). Classroom Diagnosis Room: using the characteristics of the teaching materials to select learning content (up). http://www.ied,du.hk/spfeo(poems).pdf:1

[12] Xu, H. Q., \& Hu, Z. F. (2010).The evaluation standards and implementation strategies of effective teaching. Journal of Teaching and Management, 22, 4.

[13] Tiberius, \& Tipping.(2010). Twelve Principles of Effective Teaching and Learning. http://www.utoronto.ca/tatp/handouts/Twelve_Principles_of_E ffective_Teaching.pdf:1-2

[14] The Teaching and Learning Research Programme.(2011). Effective Teaching and Learning. http://www.tlrp.org/pub/documents/TIRP_Schools_Commenta ry_FINAL.pdf:6-7

[15] Qiao, J. Z., Tao. L. P., Zhang, L. M., \& Shi, R. R. (2008). Current situation and problems of effective teaching research in China. Journal of Jiangsu Education Research(Practice Edition), 1, 32.

[16] Hao, W. W. (2009). Effective teaching method of realizing the unity of the three dimensional teaching objectives. Educational Research, 1, 69. 
[17] The Florida Center for Instructional Technology (FCIT). (2013). Classroom Interactions. http://fcit.usf.edu/assessment/attitude/survey.htm

[18] Yang, Y. D. (2006). Three kinds of teaching research activities and Enlightenment in Japan, Hong Kong and Shanghai. Exploring Education Development, (6A), 46.

[19] Li, S. Y., \& Gao, B. Y. (2007). International outlook of classroom learning research. Global Education, 1, 54. 